\title{
A stress-based fracture criteria validated on mixed microstructures of ferrite and bainite over a range of stress triaxialities
}

\author{
Stefan Golling ${ }^{\mathrm{a}, *}$, Rickad Östlund ${ }^{\mathrm{b}}$, Mats Oldenburg $^{\mathrm{a}}$ \\ ${ }^{a}$ LuleåUniversity of Technology, SE 97187 Luleå, Sweden \\ ${ }^{b}$ Gestamp HardTech, Ektjärnsvägen 5, SE 97345 Luleå
}

\begin{abstract}
Hot stamping is a sequential process for formation and heat-treatment of sheet metal components with superior mechanical properties. By applying different cooling rates, the microstructural composition and thus the material properties of steel can be designed. By controlling the cooling rate in different sections of a blank, the material properties can be tailored depending on the desired toughness. Under continuous cooling, various volume fractions of ferrite and bainite are formed depending on the rate of cooling. This paper focuses on the ductile fracture behavior of a thin sheet metal made of low-alloyed boron steel with varying amounts of ferrite and bainite. An experimental setup was applied in order to produce microstructures with different volume fractions of ferrite and bainite. In total, five different test specimen geometries, representing different stress triaxialities, were heat treated and tensile tested. Through full-field measurements, flow curves extending beyond necking and the equivalent plastic strain to fracture were determined. Experimental results were further investigated using a mean-field homogenization scheme combined with local fracture criteria. The mean-field homogenization scheme comprises the influence of microstructure composition and stress triaxiality with usable accuracy, connoting auspicious possibilities for constitutive modeling of hot-stamped components.
\end{abstract}

Keywords: ductile fracture, mean-field homogenization, digital image correlation, heat treatment, $22 \mathrm{MnB} 5$

\section{Introduction}

Vehicle manufacturers are continually trying to reduce vehicle weight, while maintaining or improving passenger safety in the event of a crash. The driving forces in the automotive industry are statutory regulations and the reduction

\footnotetext{
* Corresponding author

Email address: stefan.golling@ltu.se (Stefan Golling)
} 
of fuel consumption. The application of advanced materials and manufacturing processes are a partial reason for the increase in the crashworthiness to weight ratio. Hot stamping, also called press hardening, of low alloyed boron steel blanks is a simultaneous forming and heat-treatment process. Within the technology of hot-stamping, much effort has been placed on developing a manufacturing process that enables production of components with spatially varying properties. Components produced using this process exhibit tailored material properties in designated areas. The manufacturing process uses special tool technology, utilizing differential in-die cooling rates by heated tool sections. This technique establishes the possibility to obtain the desired microstructure and thus the desired mechanical properties, in designated areas of the final component.

In safety relevant components, where high intrusion protection and energy absorption is desired, the distribution of mechanical properties can be of advantage in the crash performance. Ferritic microstructures show high elongation before fracture and are desirable as soft zone materials in components with tailored material properties; such a material grade is obtained by low cooling rates. In transition zones of tailored components, intermediate grades containing varying volume fractions of ferrite and bainite may be formed. To gain further insight, an investigation of the influence of different volume fractions of ferrite and bainite on the ductility of quench-hardenable boron alloyed steel was conducted. A processing route was designed to produce tensile test specimens with a range of different volume fractions of ferrite and bainite. The production process of tailored material components has been investigated and modeled using an austenite decomposition model in combination with the linear rule of mixture to estimate the mechanical properties after quenching $[1,2]$. A linear rule of mixture is a simple homogenization approach; the presented model does not include fracture or damage. A variety of constitutive models that take the processing history into account have been proposed, see e.g., $[3,4,5,6]$. These models are formulated with coefficients dependent on microstructure in order to predict flow stress and ductile fracture. Mean field homogenization schemes are a common method in modeling dual- or multi-phase materials or the influence of inclusions in a matrix. Eshelby [7] developed a model describing the stress/strain field in a matrix with no interaction between inclusions. Over several decades, this approach has been improved and adjusted and shows good agreement over a wide spectrum of materials. Mori and Tanaka [8] modified the calculation of the strain concentration tensor, and in later studies, this approach was used to calculate the strain concentration and inverted concentration tensor, where the matrix and inclusion are permuted $[9,10]$. The basic modeling assumption makes use of the elastic properties of the constituents and was originally only developed for linear elastic problems. Applying this method to elasto-plastic problems requires the use of continuum or algorithmic tangent modulus [11].

The modeling of the mechanical response of multi-phase materials and ductile fracture is a field of active research. In recent studies, mean field homogenization was used to investigate the ductile fracture of aluminum and titanium plates under impact loading [12]. The influence of grain shape on the 
onset of ductile fracture in a multi-phase material was investigated using a twodimensional representative volume element (RVE) [13].

Materials consisting of two or more phases with different elastic or plastic properties are prone to mismatch among those constituents during thermal or mechanical loading. For example, mismatch due to thermal loading occurs during phase transformations. A typical example for steel is the phase transformation from austenite to martensite where a volume change occurs. If a first phase is formed, the formation of second phase will introduce stresses into the composite. Tomita and Okabayashi [14] showed that a composite of bainite and martensite has higher strength if the bainite volume fraction is small enough. Young and Bhadeshia [15] attributed this effect to the carbon enriched martensite and a constraint between the phases. Similar strengthening effects have been reported for coated bulk metallic glasses, see Chen et al. [16, 17]. In general, void nucleation and coalescence occurs at grain boundaries between grains with different microstructures. Void formation and subsequent coalescence is the precursor of crack formation. Hence, fracture is likely to originate from micro-cracks and lead to decohesion of microstructural constituents.

The stress triaxiality is a typical parameter used to describe the stress state of a material under loading. In experimental investigations, different stress triaxialities are obtained by design of test specimen with different notch radii or holes. Depending on the type of specimen, theoretical values are obtained for notched specimen geometries. For round bar specimens, the stress triaxiality can be calculated by the Bridgman equation [18]. Based on the work of Bridgman, Bai et al. [19] developed analytic equations for the cases of plane strain and plane stress notched specimens, where the notch radius and the width of the critical cross-section are the parameters used to calculate the triaxiality. The triaxiality in a critical cross-section is not constant during deformation and the validity of analytic equations is limited [20]. For specimens with other geometries, e.g., shear, combined shear-tension, and specimens with holes, inverse modeling is used to determine the stress triaxiality in the critical cross-section. For thin structures, like sheet metals, plane stress is assumed in the material. Therefore, the stress triaxialities can only be varied in the range from $-1 / 3$ (compression) to $2 / 3$ (biaxial tension). In practical applications where the lower limit is often $1 / 3$ (uniaxial tension), calibration of failure models is often performed with pure shear as the lower limit, where the triaxiality becomes equal to zero. Negative triaxiality values are also possible, e.g., in deep drawing applications where one stress component becomes negative [21]. For engineering applications, the macroscopic stress triaxiality is adequate for model calibration and the effects on the microscopic scale are neglected. At a crack tip, on a macroscopic or microscopic level, and at flaws in the form of pores or inclusions, the stress triaxiality can reach significantly higher values. Furthermore, the triaxiality at a crack tip shows a dependency on material thickness [22, 23]. Sanyal et al. [24] provide a discussion on experimental obtained fracture features under different stress states. Wierzbicki et al. [25] presented an evaluation of seven different fracture criteria, and Bai and Wierzbicki [26] extended this work and published a comparative study of different groups of fracture criteria including physics-based 
models. The correct prediction of ductile fracture over a wide range of stress triaxiality is not trivial, and a failure model needs to be chosen depending on the application. Physics-based models, such as the Gurson-Needleman-Tvergaard (GTN) model, usually need many parameters, and their calibration is often difficult and not always robust. In these models, the void formation and coalescence is of interest. A study on void evolution depending on the triaxiality in high strength dual phase steel is found in [27]. Phenomenological and empirical models usually require fewer parameters that are often easier to obtain. Calibrating a fracture model to fewer experimental points can narrow the validity range of the model to the specimen triaxialities measured. Oh et al. [28] proposed a stress-modified fracture strain model calibrated to experimental data using an exponential function and found good agreement to experimental results, not at lower stress triaxialities though. Uthaisangsuk et al. [29] studied the damage in multiphase high strength steels using representative volume element and a GTN model. The study included the variation in the phase volume fraction of martensite and its influence on failure. Mattiasson et al. [30] studied boron steel in fully hardened, martensitic condition, applying two common failure criteria, and summarized suggestions for modeling of failure in sheet forming and crash simulation. Park et al. [31] studied the effect of the martensite distribution on strain hardening and ductile fracture and Paul [32] the influence of the volume fraction on the stress triaxiality in dual phase (DP) steel.

In the field of quench-hardenable boron steel, several experimental investigations were focused on the manufacturing of components with tailored properties. Hot stamping is a thermo-mechanical process, and hence, knowledge of phase formation and influencing parameters is a necessity. The formation of different phases shows dependency on simultaneous forming and cooling. In recent years, a number of experimental investigations on the influence of deformation and cooling rate on the start temperatures of phase formation and their mechanical properties were pointed out, see [33, 34, 35]. Two different approaches are common in the investigation of properties in tailored materials and labscale components like geometries and heat-treated blanks. The first approach is aimed to mimic a large scale production cycle, while the second reduces the need for tooling. For a lab-scale tailored properties (TP) component using in-die heating and cooling, microstructural characterization revealed the formation of ferrite, bainite, and martensite for various temperature conditions in the tool [36]. By using forced air convection, different cooling rates are possible, and thus, specimens with mixed microstructures can be produced. By applying this approach, a constitutive model is calibrated to mechanical test results of produced microstructures [4]. Larger amounts of ferrite in mixed microstructures were produced by Meza-Garcia et al. [37] applying a dual furnace and tool-quenching process.

To the best of the authors' knowledge, a study on the flow behavior and ductile fracture of boron alloyed steel with direct relation to mechanical properties of the single phases ferrite and bainite over a range of stress states relevant for sheet metal applications has not yet been reported. Such a study is relevant in evaluating predictive tools for the determination of performance of compo- 
nents with tailored material properties. In the present work, a dual furnace and cartridge-heated plane tool processing system is used for the production of tensile specimens with different stress states at fracture initiation in a ferriticbainitic microstructure. The heat treatment process is presented in more detail by Golling et al. [38]. The specimen geometries used in the present work cover stress triaxialities common in sheet metal applications with special emphasizes on crash relevant components. An earlier study showed that fracture initiates in the positive range of stress triaxialities [39], and therefore, only relevant specimen geometries and loading in tension are used. Full-field deformation measurements during tensile testing combined with an evaluation routine are used to obtain data for fracture modeling and flow curves extending to large plastic strains. This approach provides a set of parameters ready to use in the constitutive model.

Östlund et al. [40] showed that a mean-field homogenization scheme combined with a ductile fracture criteria shows good agreement for mixed microstructures. It is concluded that the double-inclusion method predicts the flow behavior of multi-phase microstructures with good accuracy. The magnitude of stress vector criterion predicted fracture initiation with reasonable accuracy when compared to the experimental results. This fracture criterion is phenomenological and does not provide further insight into microstructural effects, and in the context of the present work, it is used to indicate failure. Events on the microstructural level such as void growth and coalescence are assumed to be captured by this criterion.

The aim of the present study is to further investigate the modeling approach described by Golling et al. [38] and Östlund et al. [40] by taking into account a wider range of stress states that are relevant for sheet metal applications.

\section{Experiments}

The low alloyed boron steel, $22 \mathrm{MnB} 5$, is the most common steel used in automotive hot-stamped components because of its superior hardenability. The relevance of this steel in the industry motivates the experimental investigation presented in this work. In the as delivered condition, 22MnB5 exhibits a ferriticpearlitic equiaxed, homogeneous microstructure. An AlSi coating protects the blank from oxidation during heat treatment and corrosion.

Five different specimen geometries were cut perpendicular to the rolling direction of the sheet using abrasive water jet cutting, and a thickness of $1.25 \mathrm{~mm}$ was chosen. The specimen dimensions of $240 \mathrm{~mm} 40 \mathrm{~mm}$ are governed by the size of the plane tool used for heat treatment. Specimen geometries, as depicted in Fig. 1, are chosen with the objective of generating different stress triaxialities. Prior to testing, specimen edges in the critical cross-section were polished to avoid edge specific phenomena. The cutting method and the surface quality have an influence on fracture [41] and could lead to deviation in the results.

A heat treatment process was designed with the purpose of controlling the volume fraction of the formed ferrite and bainite. The intention of this process 
is not to replicate industrial process routes but instead to achieve reliable and repeatable specimen production.
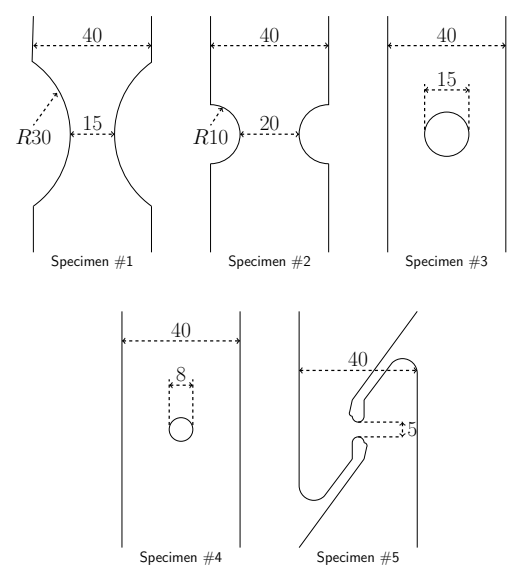

Figure 1: Overview of tensile specimens. Nominal sheet thickness is $1.25 \mathrm{~mm}$. All dimensions are in millimeters[38].

A ferritic-bainitic microstructure was chosen because of its significance in transition zones. The soft zone material in tailored properties components is usually ferritic produced by low cooling rates, although the zone material is commonly martensitic formed by quenching, e.g., high cooling rate, and in a transition zone, the cooling is an intermediate between those limit cases. The heat treatment consists of austenitization at $900^{\circ} \mathrm{C}$, maintaining the temperature at $650^{\circ} \mathrm{C}$ to form ferrite, and cooling in the plane tool heated to $430^{\circ} \mathrm{C}$. A detailed description of the heat treatment process is found in Golling et al. [42].

In total, six different microstructural compositions are used in the present study, see Tab. 1. Samples F730 and B1015 are assumed as single phases, i.e., they consist mainly of one distinct phase, and samples FB1-4 are mixtures of ferrite and bainite with different amounts of phases present, i.e., mixed microstructures consisting of mainly two distinct phases. Samples FB1-3 were characterized using SEM/EBSD imaging with a subsequent image analysis. In Fig. 2, SEM images of the ferritic-bainitic microstructure are shown.

The Vickers hardness of all samples was measured, and it is found that the hardness and ultimate tensile strength correlated linearly. A linear correlation of hardness and ultimate tensile strength is frequently reported in the literature [43]. Hence, no SEM characterization of sample FB-4 was conducted, and the phase volume fraction of present phases is estimated from the hardness correlation. In Fig. 3, the correlation of hardness to ultimate tensile strength for different mixed microstructures is summarized, and the microstructural compositions not discussed in the present work are taken from [38]. In Tab. 1, a summary of the volume fractions of present phases and the ferrite formation time used in production is depicted.

Room temperature tensile tests were performed using a servo-hydraulic ma- 


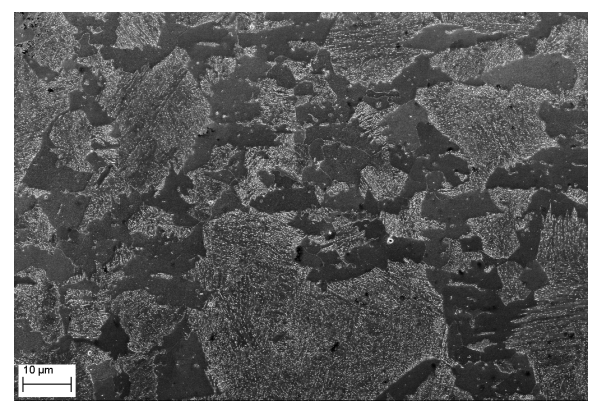

(a) Sample FB-1.

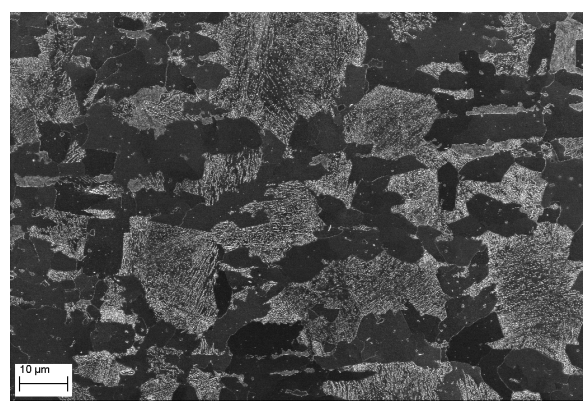

(b) Sample FB-2.

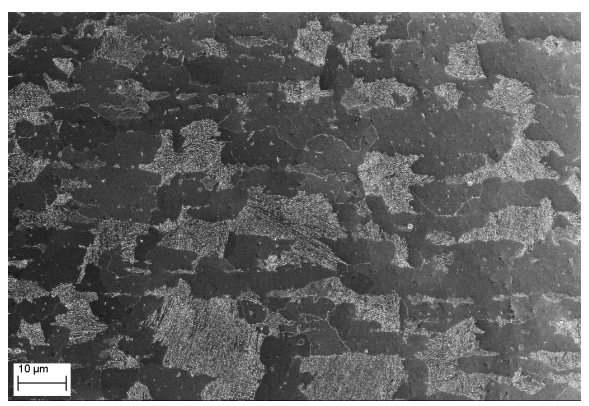

(c) Sample FB-3.

Figure 2: Examples of ferritic-bainitic microstructures from scanning electron microscope. Darker areas correspond to ferrite, and brighter areas are bainite, with cementite visualized as white dots. The area size is $120 x 80 \mu \mathrm{m}$ at a magnification of $2500 \mathrm{x}$.

chine with a cross-head displacement rate of $0.1 \mathrm{~mm} / \mathrm{s}$. Pictures for image correlation are taken with a standard CCD camera. The digital image correlation (DIC) and acquisition system Aramis (GOM GmbH, Braunschweig, Germany) were used to record the displacement field of the specimen surface during loading. If the specimen surface exhibits a random pattern, the in-plane displacement of any small unique region can be determined by a cross-correlation procedure of the digital images taken before and after deformation, [44]. After heat treatment, the AlSi coating is brittle and exhibits flaking during deformation, and therefore, sandblasting is used to remove it before the tensile testing. The specimen surface after sandblasting showed enough contrast and pattern, and hence, it was unnecessary to spray paint the specimens. During testing, three pictures were taken per second for DIC evaluation.

The determined displacement fields and force recordings constitute the basis for determining the flow curve beyond the onset of necking, as well as the stress tensor components and equivalent plastic strain values at the location and instant of fracture initiation; details of the procedure can be found in $[45,46]$. We define that the instant of fracture initiation occurs during the load step directly preceding the first detectable discontinuity in the measured displacement field. This procedure was used to extract flow and fracture data from all material 


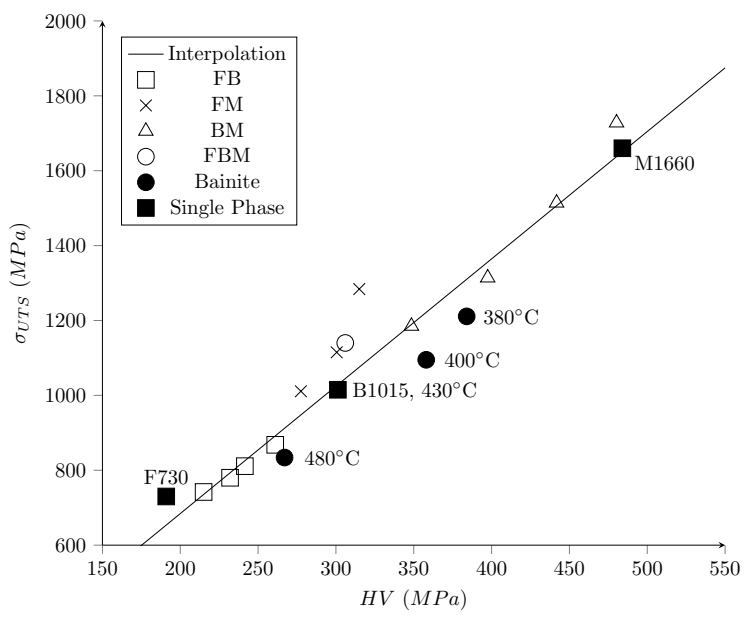

Figure 3: Correlation of Vickers hardness $(H V)$ and ultimate tensile strength $\left(\sigma_{U T S}\right)$ of $22 \mathrm{MnB} 5$ for different single phase and mixed microstructures. The influence of bainite formation temperature on hardness and $\sigma_{U T S}$ is included for four samples.

Table 1: Phase volume fraction of test samples and holding times for ferrite formation. Balance in the phase volume fraction is the amount of retained austenite.

\begin{tabular}{lcccc}
\hline Sample & $\begin{array}{c}\text { Ferrite } \\
{[\text { vol.\%] }}\end{array}$ & $\begin{array}{c}\text { Bainite } \\
{[\text { vol.\%] }}\end{array}$ & $\begin{array}{c}\text { Martensite } \\
{[\text { vol.\% }]}\end{array}$ & $\begin{array}{c}\text { Ferrite } \\
\text { formation } \\
\text { time } t_{f}[s]\end{array}$ \\
\hline F730 & 95.0 & 3.0 & $\mathrm{x}$ & air cooled \\
B1015 & $\mathrm{x}$ & 97.0 & 1.5 & air cooled \\
\hline FB-1 & 32.5 & 66.1 & 0.9 & 30 \\
FB-2 & 49.0 & 48.0 & 2.6 & 45 \\
FB-3 & 57.5 & 37.7 & 4.3 & 60 \\
FB-4 & 75.0 & 25.0 & - & 100 \\
\hline
\end{tabular}

compositions.

\section{Modelling}

In the following sections, an overview of the modeling strategy is given. The mean-field homogenization scheme was chosen after a comparative study conducted by Golling et al. [42], and the MSV fracture model suggested by Khan and Liu [47] was calibrated by Östlund et al. [48].

\subsection{Properties of constituents}

The mean-field homogenization scheme employs as input data the material grades assumed as single phase microstructures. Single phase grades are assumed to obey $J_{2}$ elasto-plasticity with isotropic hardening according to the Ludwik equation.

$$
\sigma_{Y}^{(r)}=\sigma_{Y 0}^{(r)}+K^{(r)} \bar{\varepsilon}^{(r) m_{(r)}}
$$


where $\sigma_{Y 0}^{(r)}, K^{(r)}$ and $m_{(r)}$ are the initial yield stress, strength coefficient, and hardening exponent of phase $r$, respectively. It is further assumed that differences in isotropic elastic properties of the constituents are negligible, rendering a homogeneous elastic response.

\subsection{Mean-field homogenization}

To gain further insight into the deformation and fracture behavior of the different ferritic-bainitic microstructures produced, micromechanical modeling was performed. In mean-field techniques, the local strain and stress fields within each constituent are expressed through their phase averages $\langle\bullet\rangle_{(r)}$,

$$
\langle\sigma\rangle_{(r)}=\frac{1}{\Omega_{r}} \int_{\Omega_{r}} \sigma d \Omega, \quad\langle\varepsilon\rangle_{(r)}=\frac{1}{\Omega_{r}} \int_{\Omega_{r}} \varepsilon d \Omega
$$

where $\Omega_{r}$ is the subdomain occupied by phase $r$ within the representative volume element (RVE) domain $\Omega$. The average fields over the entire RVE domain, which correspond to the applied macroscopic fields, are given as

$$
\langle\sigma\rangle=\sum_{r} v_{r}\langle\sigma\rangle_{(r)}, \quad\langle\varepsilon\rangle=\sum_{r} v_{r}\langle\varepsilon\rangle_{(r)}
$$

where $v_{r}=\Omega^{r} / \Omega$ is the volume fraction of phase $(r)$. The per-phase average stress and strain fields are related to the overall fields by the stress and strain concentration tensors through where $\Omega_{r}$ is the subdomain occupied by phase $r$ within the representative volume element (RVE) domain $\Omega$.

$$
\langle\sigma\rangle_{(r)}=\mathbf{A}_{(r)}:\langle\sigma\rangle, \quad\langle\varepsilon\rangle_{(r)}=\mathbf{B}_{(r)}:\langle\varepsilon\rangle .
$$

The per-phase average stress and strain fields are related to the overall fields by stress and strain concentration tensors. Mean field homogenization schemes differ in their expression of the concentration tensors. The majority of these schemes rely on the solution of Eshelby [7] solving for the elastic field of a single inclusion embedded in an infinite matrix. In this approach, no interactions between inhomogeneities at non-dilute concentrations are taken into account. Mori and Tanaka [8] introduced the average matrix fields into Eqs. 4 replacing the macroscopic fields. Hence, the average strain in the inclusion $r$ is,

$$
\langle\varepsilon\rangle_{(r)}=\mathbf{B}_{(r)}:\langle\varepsilon\rangle_{(m)}
$$

where subscript $m$ denotes the matrix phase and $\mathbf{B}_{(r)}$ the concentration tensor for the single inclusion. The strain concentration tensor in 5 is defined as,

$$
\mathbf{B}_{(r)}=\left[\mathbf{I}+\mathcal{E}:\left(\left(\mathbf{D}_{(m)}^{e}\right)^{-1}: \mathbf{D}_{(r)}^{e}-\mathbf{I}\right)\right]^{-1} .
$$

where $\mathbf{I}$ is the fourth order identity tensor, $\mathcal{E}$ is the Eshelby tensor, and $\mathbf{D}_{(r)}^{e}$ and $\mathbf{D}_{(m)}^{e}$ arethe Hooke's elasticity tensor for inclusion phase $r$ and the matrix phase, respectively. For isotropic elasticity, the Eshelby tensor depends only 
on the semi-axes of the elliptic inclusion and the Poisson's ratio of the matrix [49]. In real microstructures, non-dilute concentrations of inclusion phases are dispersed in a distinct matrix phase and may form continuous networks. To take such microstructural effects into account, we employ an interpolation between the regular Mori-Tanaka (MT) model, and the inverse of it where the material properties of inclusion and matrix are permuted. This homogenization approach was proposed by Hori and Nemat-Nasser [9] and further explored by Lielens et al. [10] and Doghri and Ouaar [11], and it is referred to as the double inclusion (DI) model. In the form of incremental elasto-plasticity, the average strain rate of inclusion phase $r$ is related to the average matrix strain rate by

$$
\begin{aligned}
& \langle\dot{\varepsilon}\rangle_{(r)}=\mathbf{B}_{(r)}:\langle\dot{\varepsilon}\rangle_{(m)}, \quad \text { where } \\
& \mathbf{B}_{(r)}=\left[(1-\xi) \mathbf{B}_{(r)}^{l}+\xi \mathbf{B}_{(r)}^{u}\right]^{-1} \text { and } \\
& \mathbf{B}_{(r)}^{l}=\left[\mathbf{I}+\mathcal{E}_{(m)}:\left(\mathbf{D}_{(m)}^{-1}: \mathbf{D}_{(r)}-\mathbf{I}\right)\right]^{-1}, \\
& \mathbf{B}_{(r)}^{u}=\mathbf{I}+\mathcal{E}_{(r)}:\left(\mathbf{D}_{(r)}^{-1}: \mathbf{D}_{(m)}-\mathbf{I}\right) .
\end{aligned}
$$

where $\mathbf{B}_{(r)}^{l}, \mathbf{B}_{(r)}^{u}$ are the regular and inverse MT strain concentration tensors, respectively. $\xi\left(v_{r}\right)$ is a smooth interpolation function. Furthermore, $\mathbf{D}_{(r)}$ and $\mathbf{D}_{(m)}$ are reference tangent moduli of inclusion phase $r$ and the matrix phase, as computed with the average strain rates of that phase, and $\mathcal{E}_{(m)}$ and $\mathcal{E}_{(r)}$ denote the Eshelby tensor computed using the matrix or the inclusion reference moduli, respectively. The implementation of the homogenization scheme is described in more detail in $[40,38]$ and is largely based on the work of Doghri and Ouaar [11], where additional details and discussions are found.

\subsection{Ductile fracture}

Fracture is defined as the separation of a body into two or more pieces in response to an imposed stress. Most fracture damage theories are characterized by a mean stress dependence. The mean stress $\bar{\sigma}^{\text {mean }}$ is normalized to the effective stress $\bar{\sigma}$ leading to the dimensionless stress triaxiality parameter $\eta$. The stress triaxiality parameter characterizes all loading conditions in a plane state of stress.

$$
\eta=\frac{\bar{\sigma}^{\text {mean }}}{\bar{\sigma}} \quad \text { with, } \quad \bar{\sigma}^{\text {mean }}=\frac{I_{1}}{3} \quad \text { and } \quad \bar{\sigma}=\sqrt{3 J_{2}}
$$

where $I_{1}$ is the first stress invariant and $J_{2}$ is the second deviatoric invariant of the stress tensor. The progressive nucleation, growth, and coalescence of micro-voids during plastic loading ultimately lead to macroscopic crack initiation in ductile metals. This mechanism is influenced by the microscopical field quantities and the nucleation/growth resistance of each constituent phase and interfaces present. We consider the nucleation process as being the dominant 
factor, and assume that this process is mainly controlled by the local average stress field acting on microscopic scale.

It is assumed that the strength of the phases is governed by a ductile fracture criterion in the form suggested in [47], abbreviated as the MSV criterion. The MSV criterion involves the magnitude of the stress vector, $M S V$,

$$
M S V=\left(\sigma_{1}^{2}+\sigma_{2}^{2}+\sigma_{3}^{2}\right)^{1 / 2}=\left(3\left(\bar{\sigma}^{\text {mean }}\right)^{2}+\frac{2}{3} \bar{\sigma}^{2}\right)^{1 / 2}
$$

as the fracture indicator, where $\sigma_{i}, i=1,2,3$ are the principal stresses, and the criterion is given by

$$
M S V=c_{1}\left(\bar{\sigma}^{\text {mean }}\right)^{2}+c_{2} \bar{\sigma}^{\text {mean }}+c_{3},
$$

where $\bar{\sigma}^{\text {mean }}$ is the mean stress and $c_{1}-c_{3}$ are the model parameters. Two different quadratic expressions for the positive and negative mean stress regions are suggested [47]. We consider only the positive region as being of relevance for thin-walled structures. This criterion is established in terms of the microscopical average stress acting within each phase, so that Eqs. $(9,10)$ read

$$
\begin{aligned}
\langle M S V\rangle_{(r)} & =\left(3\left\langle\bar{\sigma}^{\text {mean }}\right\rangle_{(r)}^{2}+\frac{2}{3}\langle\bar{\sigma}\rangle_{(r)}^{2}\right)^{1 / 2} \\
\langle M S V\rangle_{(r)} & =c_{1(r)}\left\langle\bar{\sigma}^{\text {mean }}\right\rangle_{(r)}^{2}+c_{2(r)}\left\langle\bar{\sigma}^{\text {mean }}\right\rangle_{(r)}+c_{3(r)},
\end{aligned}
$$

where $\langle\bar{\sigma}\rangle_{(r)}$ and $\left\langle\bar{\sigma}^{\text {mean }}\right\rangle_{(r)}$ are the local average effective stress and mean stress, respectively, acting within phase $(r)$. Failure on macroscopic level is assumed if the fracture criterion is fulfilled for a phase, i.e., the weakest link on the microscopic level fails.

\subsection{Parameter estimation}

Before the micromechanical simulations, constitutive data including fracture parameters for each constituent phase, i.e., ferrite and bainite, are needed. The parameters were obtained in an earlier study, see [48], and are reproduced in Tab. 2. Experimental results and calibrated functions are shown in Fig. 4. These parameters are obtained from plasticity and fracture experiments, as described in Sec. 2, using specimens consisting of predominantly one constituent phase.

\section{Results and discussion}

\subsection{Macroscopic flow behavior}

Four different ferritic-bainitic phase volume fractions are presented, and for samples FB-1 to FB-3, only specimen geometry \#1 was produced and included, whereas for sample FB-4, all specimen geometries were produced and analyzed. 
Table 2: Material parameters for ferrite and bainite calibrated in the work of Östlund et al. [48].

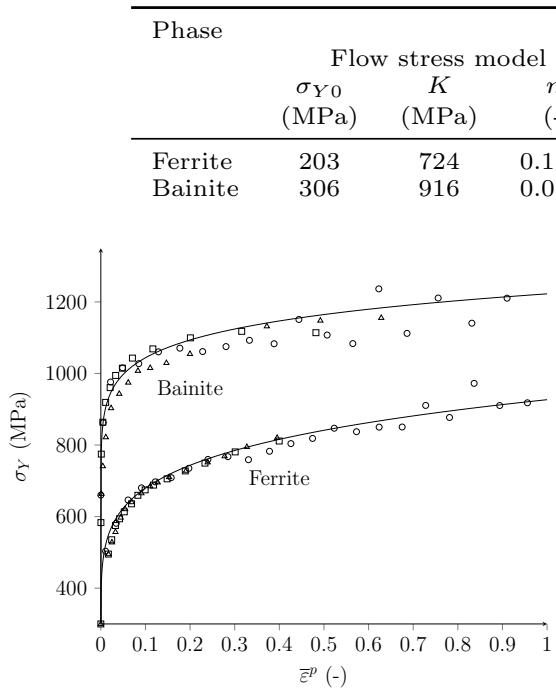

(a) Flow curves.

\begin{tabular}{ccc}
\multicolumn{3}{c}{ Parameter } \\
Fracture criterion \\
$c_{1}$ & $c_{2}$ & $c_{3}$ \\
$(\mathrm{MPa})^{-1}$ & $(-)$ & $(\mathrm{MPa})$ \\
\hline $1.284 \mathrm{e}-3$ & 0.1093 & 755.0 \\
$6.564 \mathrm{e}-4$ & 0.2997 & 996.4
\end{tabular}

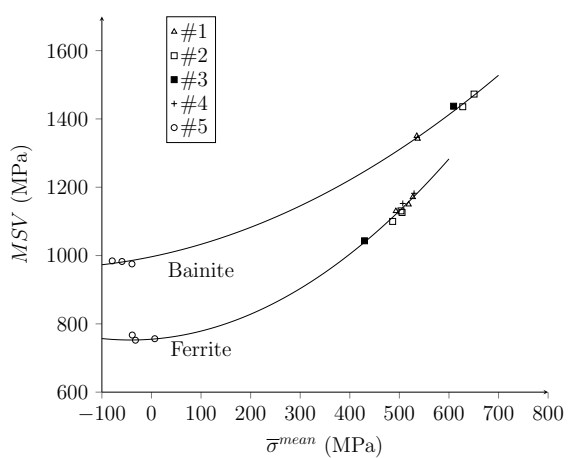

(b) Fracture limit curves.

Figure 4: Flow and fracture limit curves for each constituent phase. In (a), the power-law fit and the corresponding points obtained from experiments and image correlation. The fracture criterion is illustrated in (b), where squares, triangles, etc., indicate the fracture initiation as obtained from experiments, and the solid lines represent the fracture limit curves according to the MSV criterion. The legend entries in (b) refer to the test specimen number as depicted in Fig. 1, and applies to (a) and (b).

For microstructural composition, the reader is referred to Tab. 1 and for specimen geometries to Fig. 1. The focus in this work is on the predictive capabilities of the constitutive model over a range of stress triaxialities found in sheet metal applications of mixed microstructure. The overall flow behavior for dual-phase, ferrite-bainite microstructures, is shown in Fig. 5. For all phase volume fractions, experimental results obtained for specimen geometry \#1 are compared to results predicted by the DI model. These flow curves extend beyond the onset of necking, up to large strains. A general observation is the good agreement between measured and predicted results. The main source for discrepancies in the prediction of mixed microstructures is the uncertainty of the present phase volume fractions.

\subsection{Macroscopic ductility}

The influence of different phase compositions on the overall ductility is shown in Fig. 6. The constitutive model was integrated using a constant stress triaxiality of $\eta=0.57$, which corresponds to an average value obtained by experimental analysis of specimen geometry \#1. The measured and calculated overall ductility is illustrated in the space of macroscopic equivalent fracture strain $\bar{\epsilon}^{f}$ and 


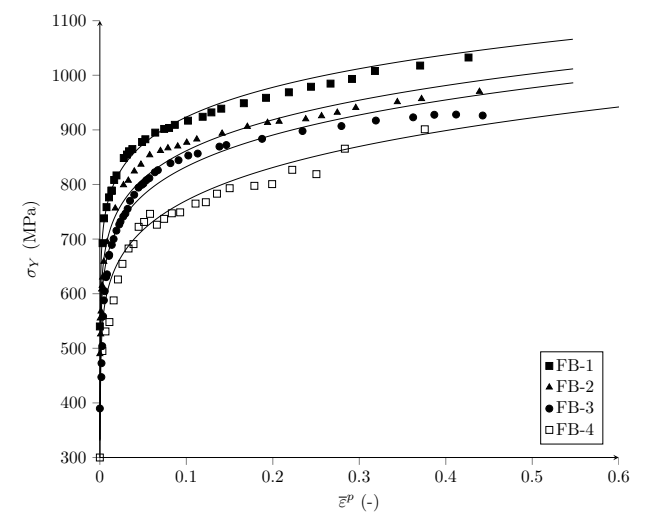

Figure 5: Experimentally obtained and predicted flow curves of ferrite-bainite composites.

the relative volume content of constituent phase. Ferrite is seen as the continuous phase even at high volume fractions of bainite, and is hence assumed as the matrix phase. For spherical inclusions of uniform size, a content above the maximum packing concentration of $\left(v_{i}\right)_{\max } \approx 0.75$ is physically not meaningful, and hence, calculations for higher volume fractions of bainite are not included.

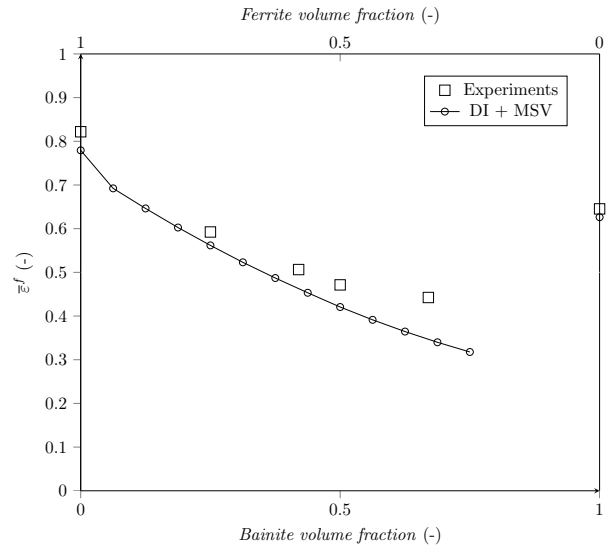

Figure 6: Ferrite matrix with bainitic inclusions. Results obtained by a constant triaxiality corresponding to specimen geometry \#1.

Permuting bainite to matrix and ferrite to the inclusion phase is feasible but it did not prove to yield a change in the results. The reason for equal results with permuted phases is the strain/stress concentration into the ferrite phase indicating failure, even for low amounts of ferrite in a bainitic matrix. Experimental results suggested that at a volume fraction of about $25 \%$ bainite in a ferritic matrix, the overall ductility diminishes compared to the single phase bainitic microstructure.

Concerning the predicted results, the model indicates fracture in ferrite, irre- 
spective of whether it is set as matrix or inclusion phase, for all volume fractions reported. The double inclusion model is used to calculate the macroscopic strain of the composite material based on the local strain field in the phases. Local strain levels differ because of divergent properties of ferrite from bainite. This mismatch explains the indication of fracture in ferrite, and the strain partition into ferrite sequentially increases the stress level. The combination of the DI model and MSV fracture criterion underpredicted experimental results for all present phase compositions. A possible explanation for this is the use of a constant stress triaxiality. The stress distribution within an RVE depends on the reference moduli, which are history dependent, and hence introduces a slight path dependence on the overall ductility predictions by the DI-model. The ductile fracture criterion is formulated in the local average stress space and is path independent.

Table 3: Fracture strain of specimens with geometry \#1.

\begin{tabular}{lccc}
\hline Sample & Experiment & DI-model & Relative error \\
\hline F730 & 0.822 & 0.779 & 0.052 \\
B1015 & 0.645 & 0.626 & 0.029 \\
\hline FB-1 & 0.442 & 0.347 & 0.215 \\
FB-2 & 0.471 & 0.421 & 0.106 \\
FB-3 & 0.506 & 0.463 & 0.085 \\
FB-4 & 0.592 & 0.562 & 0.051
\end{tabular}

Evaluation of the DIC results show a variation of stress triaxiality towards plane strain, i.e., during tensile loading, the specimen geometry changes and influences the triaxiality parameter. This behavior is less pronounced in brittle materials, e.g., martensitic microstructures, but is pronounced in more ductile materials with larger deformation. The observation of the inconsistent stress triaxiality has been reported by Selini et al. [20] as well. Tab. 3 summarizes all microstructures of specimen geometry \#1 and compares the experimental and modeling results.

\subsection{Ductility at different stress states}

For sample FB-4, digital speckle measurements on five different specimen geometries were conducted. From the obtained displacement fields, the flow curve up to strains beyond the onset of necking, as well as the stress tensor components and equivalent plastic strain values over the full field, were determined. The equivalent plastic strain prior to fracture is termed equivalent fracture strain $\bar{\epsilon}^{f}$. The measured displacements represent the deformation of the surface of the test specimen, and in turn, the macroscopic response of a dual-phase microstructure under loading. Macroscopic image correlation provides no further information of strain partition on the microscopic level. Hence, with the experimental technique used in the present study, the effect of elastic mismatch between the phases cannot be observed directly.

In Fig. 7 and Tab. 4, experimental and predicted results for the dual phase microstructure termed FB-4 are compared over a range of stress triaxial- 


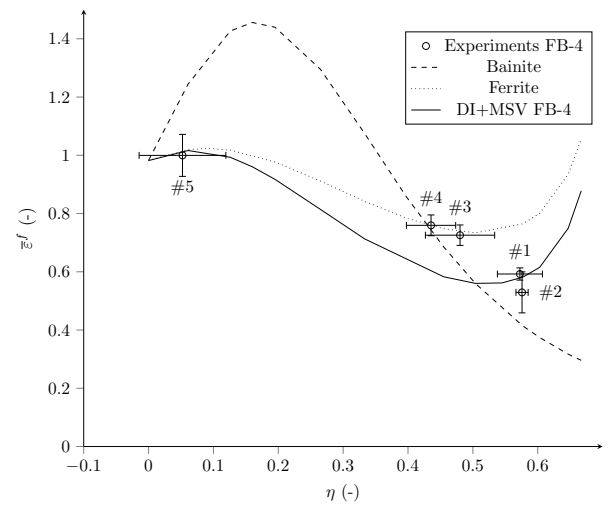

Figure 7: Strain at fracture at different stress triaxialities for sample FB-4.

Table 4: Measured fracture strain, stress triaxiality, and standard deviation for the five specimen geometries of sample FB-4.

\begin{tabular}{ccccc}
\hline & $\bar{\eta}$ & $s_{\eta}$ & $\bar{\epsilon}^{f}$ & $s_{\bar{\epsilon} f}$ \\
\hline$\# 1$ & 0.573 & 0.035 & 0.592 & 0.021 \\
$\# 2$ & 0.576 & 0.009 & 0.529 & 0.070 \\
$\# 3$ & 0.480 & 0.053 & 0.726 & 0.035 \\
$\# 4$ & 0.436 & 0.038 & 0.759 & 0.036 \\
$\# 5$ & 0.052 & 0.067 & 0.999 & 0.072
\end{tabular}

ities. Fracture of the mixed microstructure is assumed if one of the constituents reaches its critical value, i.e., the weakest link in the microstructure fails.

A general observation is that the composite does not exceed the fracture strain of a single phase microstructure. This is attributed to the mismatch between the ferrite and bainite, causing interphase stresses and thus reducing the overall ductility. In the predicted results, fracture is indicated in ferrite for all specimen geometries. The failure model used does not include an interphase fracture criterion, and therefore, no distinction between failure in a phase or the interface to the neighboring phase is made.

Specimen geometries were not available for triaxiality values between pure shear and pure tension. Thus, it is unknown if the calibration for single phase microstructures is valid in this region and similar to the prediction of the mixed microstructure.

For triaxialities up to $\eta=0.5$, the measured results agree well with calibrated results of the single phase ferrite. These results support the assumption of the weakest link criterion, i.e., strain localizes into ferrite and leads to fracture. For samples with higher triaxialities, specimen \#1 and \#2, fracture is also indicated in ferrite but occurs earlier compared to the single phase microstructure. By using the DI-model, the macroscopic strain at fracture is calculated, and this strain value corresponds to the plastic strain in the mixed microstructure at the point where the weakest link fails. The predicted fracture strain of the mixed microstructure and the experimental observation of specimens \#1 and 
\#2 show good agreement. This is taken as an indication that for higher stress triaxialities, the fracture prediction in a composite needs a different approach in modeling.

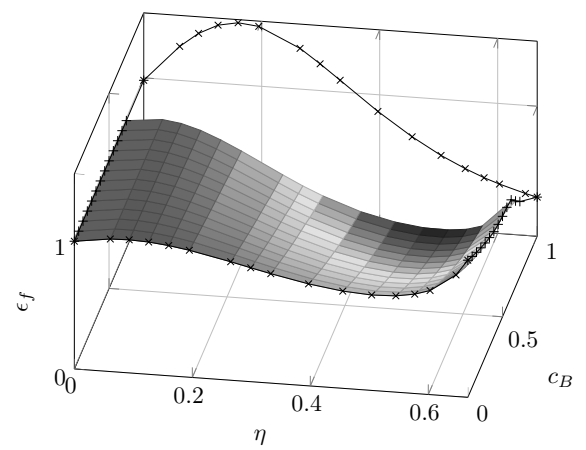

(a)

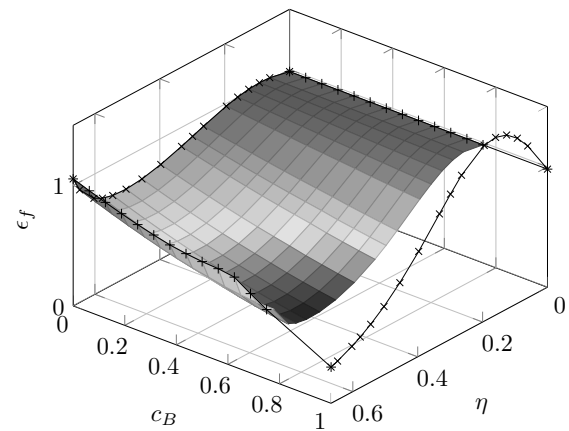

(b)

Figure 8: Equivalent fracture strain of the composite material at different stress triaxialities and phase volume fractions.

By using the constitutive model presented in Sec. 3, the fracture strain and its dependence on stress triaxiality and phase volume fraction are displayed in Fig. 8. The first boundary value for sheet metals is pure shear, and no influence on the fracture strain by the phase composition was observed for the single phase microstructures. Hence, it is expected that a mixed microstructure shows the depicted behavior. The second boundary value is equi-biaxial loading. At this point, both single phase microstructures showed different fracture strains. The constitutive model predicts a reduction in fracture strain with a plateau at a volume fraction of bainite $v_{B}=0.45-0.63$, followed by a drop in fracture strain until the critical volume fraction of the inclusion phase is reached.

\subsection{Uncertainties}

Identification of material properties of individual constituents is a difficulty in the application of homogenization methods. In this work, it is assumed that (i) the single phase specimens can be considered to be homogeneous, and that (ii) the measured properties obtained from macroscopic tensile tests can describe the in-situ response of the constituent at the microscale. The specimens are heterogeneous to some degree, and thus, these assumptions are not strictly valid. Mixed microstructures consist of proeutectoid ferrite and bainite. Contrary to mixed microstructures, sample F730 is irregular ferritic, and the resemblance of mechanical properties to proeutectoid ferrite is difficult to estimate. The mechanical properties of bainite are strongly dependent on its formation temperature, see Fig. 3 for comparison of four different formation temperatures. The extent of correlation of sample B1015, which solely consist of bainite, to the bainite found in mixed microstructures is unknown to the authors. As the bainite formation temperature is equal for single- and multiphase 
samples, agreement in properties is assumed. During ferrite formation, the remaining austenite is enriched in carbon content, but its influence on properties of bainite is neglected. Likewise, the local chemical composition, which has influence on the mechanical properties of the constituents, will be altered by heat treatment and is not considered.

Moreover, the simplifications inherent to the MFH scheme relative to the physics of the problem, such as phase-wise constant fields, topological simplifications, and strict validity only to small strains, in combination with local fracture criteria, are certainly debatable. The present approach shows a viable way forward for the microstructure-based modeling of ductile fracture initiation in press-hardened steels, but more research is needed in order to quantify these aforementioned uncertainties.

SEM micrographs are taken from small regions of the tensile specimens to determine the present phase volume fractions in samples FB-1 to FB-3. The variation within this small region was estimated to be about $\pm 2-4 \%$. In an earlier study, two independent characterizations, both using the same method, were compared, and an indication for higher uncertainties was found. Hardness measurements across the gauge length showed no significant variation. Henceforth, processing conditions ensure an even temperature distribution within the gauge length. Sample FB-4 was characterized by hardness correlation, and in this case, measurements also showed little variation.

Fracture strain evaluation was performed on five different specimen geometries, and for every geometry, seven samples were heat treated. Variation in strain to fracture and triaxiality is expected, and the average values and mean standard deviation are shown in Fig. 7.

\section{Conclusion}

A mean-field homogenization scheme based on Eshelby's inclusion theory is combined with the magnitude of stress vector (MSV) fracture criterion. The constitutive model is calibrated using measured data of single phase microstructures, ferrite and bainite. By using a heat treatment procedure, a series of ferritic-bainitic microstructures are produced, and for one specific microstructural composition, a set of five different specimen geometries, representing different stress states, are available. By using digital image correlation and forceelongation measurements, the flow and fracture properties of these specimens are characterized. The mean-field homogenization scheme predicts the hardening of mixed microstructures with varying amount of ferrite and bainite, with reasonable accuracy. The MSV fracture criterion used as an indicator for composite fracture applied in a weakest link assumption showed good agreement between the experimental and predicted results over the range of triaxialities relevant for sheet metal applications, with an emphasis on crash relevant components. 


\section{Acknowledgments}

Economic support for this work was supplied by VINNOVA through the project FFI OPTUS2 nr 2009-04597, which is gratefully acknowledged. The authors wish to acknowledge the supply of blanks by Gestamp HardTech Luleå. Hans Åhlin is acknowledged for his support in the design of the tool used in this study. Also, the assistance with experiment execution by Mr. Jan Granström is acknowledged.

\section{References}

[1] Åkerström P, Oldenburg M. Austenite decomposition during press hardening of a boron steel: computer simulation and test. Journal of Materials Processing Technology 2006;174(1-3):399-406. doi:http://dx.doi.org/10.1016/j.jmatprotec.2006.02.013.

[2] Åkerström P, Bergman G, Oldenburg M. Numerical implementation of a constitutive model for simulation of hot stamping. Modelling and Simulation in Materials Science and Engineering 2007;15(2):105. doi:http://dx.doi.org/10.1088/0965-0393/15/2/007.

[3] Östlund R, Berglund D, Oldenburg M. Failure model evaluation for varying microstructure base on material hardness. In: Oldenburg M, Prakash B, Steinhoff K, editors. Hot sheet metal forming of high performance steel. Verlag Wissenschaftliche Scripten; 2011, p. 41-8.

[4] Bardelcik A, Worswick MJ, Winkler S, Wells MA. A strain rate sensitive constitutive model for quenched boron steel with tailored properties. International Journal of Impact Engineering 2012;50(0):49 - 62. doi:http://dx.doi.org/10.1016/j.ijimpeng.2012.06.007.

[5] Bardelcik A, Worswick MJ, Wells MA. The influence of martensite, bainite and ferrite on the as-quenched constitutive response of simultaneously quenched and deformed boron steel - experiments and model. Materials \& Design 2014;55(0):509 -25. doi:http://dx.doi.org/10.1016/j.matdes.2013.10.014.

[6] Eller TK, Greve L, Andres MT, Medricky M, Hatscher A, Meinders VT, et al. Plasticity and fracture modeling of quench-hardenable boron steel with tailored properties. Journal of Materials Processing Technology 2014;214(6):1211 $\quad$-27. doi:http://dx.doi.org/10.1016/j.jmatprotec.2013.12.015.

[7] Eshelby JD. The determination of the elastic field of an ellipsoidal inclusion, and related problems. Proceedings of the Royal Society of London Series A Mathematical and Physical Sciences 1957;241(1226):376-96. doi:10.1098/rspa.1957.0133. 
[8] Mori T, Tanaka K. Average stress in matrix and average elastic energy of materials with misfitting inclusions. Acta Metallurgica 1973;21(5):571 -4. doi:http://dx.doi.org/10.1016/0001-6160(73)90064-3.

[9] Hori M, Nemat-Nasser S. Double-inclusion model and overall moduli of multi-phase composites. Mechanics of Materials 1993;14(3):189 - 206. doi:http://dx.doi.org/10.1016/0167-6636(93)90066-Z.

[10] Lielens G, Pirotte P, Couniot A, Dupret F, Keunings R. Prediction of thermo-mechanical properties for compression moulded composites. Composites Part A: Applied Science and Manufacturing 1998;29(12):63 70. doi:http://dx.doi.org/10.1016/S1359-835X(97)00039-0; selected Papers Presented at the Fourth International Conference on Flow Processes in Composite Material.

[11] Doghri I, Ouaar A. Homogenization of two-phase elasto-plastic composite materials and structures: Study of tangent operators, cyclic plasticity and numerical algorithms. International Journal of Solids and Structures 2003;40(7):1681 -712. doi:http://dx.doi.org/10.1016/S00207683(03)00013-1.

[12] Xiang M, Chen J. Numerical simulation of ductile fracture based on mean field homogenization method: Modeling and implementation. Engineering Fracture Mechanics 2015;:doi:http://dx.doi.org/10.1016/j.engfracmech.2015.07.041.

[13] de Geus T, Peerlings R, Geers M. Microstructural modeling of ductile fracture initiation in multi-phase materials. Engineering Fracture Mechanics 2015;147:318 -30. doi:http://dx.doi.org/10.1016/j.engfracmech.2015.04.010.

[14] Tomita Y, Okabayashi K. Improvement in lower temperature mechanical properties of 0.40 pct c-ni-cr-mo ultrahigh strength steel with the second phase lower bainite. Metallurgical Transactions A 1983;14(2):485-92. doi:http://dx.doi.org/10.1007/BF02644225.

[15] Young CH, Bhadeshia HKDH. Strength of mixtures of bainite and martensite. Materials Science and Technology 1994;10(3):209-14. doi:http://dx.doi.org/10.1179/mst.1994.10.3.209.

[16] Chen W, Chan K, Yu P, Wang G. Encapsulated zr-based bulk metallic glass with large plasticity. Materials Science and Engineering: A 2011;528(6):2988 -94. doi:http://dx.doi.org/10.1016/j.msea.2010.12.077.

[17] Chen W, Chan K, Chen S, Guo S, Li W, Wang G. Plasticity enhancement of a zr-based bulk metallic glass by an electroplated cu/ni bilayered coating. Materials Science and Engineering: A 2012;552:199 - 203. doi:http://dx.doi.org/10.1016/j.msea.2012.05.031. 
[18] Bridgman PW. Studies in Large Plastic Flow and Fracture. 2. rev. ed.; New York: McGraw-Hill; 1952. ISBN 90-247-3343-X.

[19] Bai Y, Teng X, Wierzbicki T. On the application of stress triaxiality formula for plane strain fracture testing. Journal of Engineering Materials and technology 2009;131(2):021002.

[20] Selini N, Elmeguenni M, Benguediab M. Effect of the triaxiality in plane stress conditions. Engineering, Technology \& Applied Science Research $2013 ; 3(1): 373-80$.

[21] Pineau A, Benzerga A, Pardoen T. Failure of metals i: Brittle and ductile fracture. Acta Materialia 2016;107:424 -83 . doi:http://dx.doi.org/10.1016/j.actamat.2015.12.034.

[22] Chen W, Liu Z, Ketkaew J, Mota RMO, Kim SH, Power M, et al. Flaw tolerance of metallic glasses. Acta Materialia 2016;107:220 -8. doi:http://dx.doi.org/10.1016/j.actamat.2016.02.002.

[23] Chen W, Ketkaew J, Liu Z, Mota RMO, OBrien K, da Silva CS, et al. Does the fracture toughness of bulk metallic glasses scatter? Scripta Materialia 2015;107:1 - 4. doi:http://dx.doi.org/10.1016/j.scriptamat.2015.05.003.

[24] Sanyal G, Das A, Singh J, Chakravartty J. Effect of notch geometry on fracture features. Materials Science and Engineering: A 2015;641:210 -4. doi:http://dx.doi.org/10.1016/j.msea.2015.06.044.

[25] Wierzbicki T, Bao Y, Lee YW, Bai Y. Calibration and evaluation of seven fracture models. International Journal of Mechanical Sciences 2005;47(45):719 -43. doi:http://dx.doi.org/10.1016/j.ijmecsci.2005.03.003.

[26] Bai Y, Wierzbicki T. A comparative study of three groups of ductile fracture loci in the 3d space. Engineering Fracture Mechanics 2015;135(0):147 -67. doi:http://dx.doi.org/10.1016/j.engfracmech.2014.12.023.

[27] Hug E, Martinez M, Chottin J. Temperature and stress state influence on void evolution in a high-strength dual-phase steel. Materials Science and Engineering A 2015;626:286-95. doi:10.1016/j.msea.2014.12.053.

[28] Oh CS, Kim NH, Kim YJ, Baek JH, Kim YP, Kim WS. A finite element ductile failure simulation method using stress-modified fracture strain model. Engineering Fracture Mechanics 2011;78(1):124 -37. doi:http://dx.doi.org/10.1016/j.engfracmech.2010.10.004.

[29] Uthaisangsuk V, Prahl U, Bleck W. Modelling of damage and failure in multiphase high strength DP and TRIP steels. Engineering Fracture Mechanics 2011;78(3):469 -86. doi:http://dx.doi.org/10.1016/j.engfracmech.2010.08.017; mesoMechanical Modelling of Fatigue and Fracture. 
[30] Mattiasson K, Jergus J, DuBois P. On the prediction of failure in metal sheets with special reference to strain path dependence. International Journal of Mechanical Sciences 2014;88:175 -91. doi:http://dx.doi.org/10.1016/j.ijmecsci.2014.08.006.

[31] Park K, Nishiyama M, Nakada N, Tsuchiyama T, Takaki S. Effect of the martensite distribution on the strain hardening and ductile fracture behaviors in dual-phase steel. Materials Science and Engineering A 2014;604:13541. doi:10.1016/j.msea.2014.02.058.

[32] Paul SK. Effect of martensite volume fraction on stress triaxiality and deformation behavior of dual phase steel. Materials and Design 2013;50:782 -9. doi:http://dx.doi.org/10.1016/j.matdes.2013.03.096.

[33] Min J, Lin J, Min Y, Li F. On the ferrite and bainite transformation in isothermally deformed 22mnb5 steels. Materials Science and Engineering: A 2012;550:375 -87. doi:http://dx.doi.org/10.1016/j.msea.2012.04.091.

[34] Chang Y, Li X, Zhao K, Wang C, Zheng G, Hu P, et al. Influence of stress on martensitic transformation and mechanical properties of hot stamped AHSS parts. Materials Science and Engineering: A 2015;629:1 7. doi:http://dx.doi.org/10.1016/j.msea.2015.01.056.

[35] Nikravesh M, Naderi M, Akbari G. Influence of hot plastic deformation and cooling rate on martensite and bainite start temperatures in 22mnb5 steel. Materials Science and Engineering: A 2012;540:24 -9. doi:http://dx.doi.org/10.1016/j.msea.2012.01.018.

[36] George R, Bardelcik A, Worswick MJ. Hot forming of boron steels using heated and cooled tooling for tailored properties. Journal of Materials Processing Technology 2012;212:2386-99. doi:http://dx.doi.org/10.1016/j.jmatprotec.2012.06.028.

[37] Meza-Garcia E, Mosel A, Shchus Y, Rautenstrauch A, Lachmann L, Schieck $\mathrm{F}$, et al. Design of heat treatment processes for a tailored set of properties on $22 \mathrm{mnb} 5$ steel alloy sheets simulation and experiments. In: Oldenburg M, Steinhoff K, Parkash B, editors. Hot sheet metal forming of high-performance steel, CHS2: 4th international conference. Verlag Wissenschaftliche Scripten; 2013, p. 337-44.

[38] Golling S, Östlund R, Oldenburg M. Characterization of ductile fracture properties of quench-hardenable boron steel: Influence of microstructure and processing conditions. Materials Science and Engineering: A 2016;658:472 -83. doi:http://dx.doi.org/10.1016/j.msea.2016.01.091.

[39] Östlund R, Berglund D, Oldenburg M. Failure analysis of a hat profile with tailored properties subjected to axial compression. In: Oldenburg M, Prakash B, Steinhoff K, editors. Hot sheet metal forming of high performance steel. Verlag Wissenschaftliche Scripten; 2013, p. 23-30. 
[40] Östlund R, Golling S, Oldenburg M. Microstructure based modeling of ductile fracture initiation in press-hardened sheet metal structures. Computer Methods in Applied Mechanics and Engineering 2016;302:90 - 108. doi:http://dx.doi.org/10.1016/j.cma.2015.11.035.

[41] Wang K, Luo M, Wierzbicki T. Experiments and modeling of edge fracture for an AHSS sheet. International Journal of Fracture 2014;187(2):245-68. doi:10.1007/s10704-014-9937-5.

[42] Golling S, Östlund R, Oldenburg M. A study on homogenization methods for steels with varying content of ferrite, bainite and martensite. Journal of Materials Processing Technology 2016;228:88-97. doi:http://dx.doi.org/10.1016/j.jmatprotec.2015.07.007.

[43] Zhang P, Li S, Zhang Z. General relationship between strength and hardness. Materials Science and Engineering: A 2011;529:62 - 73. doi:http://dx.doi.org/10.1016/j.msea.2011.08.061.

[44] Kajberg J, Lindkvist G. Characterisation of materials subjected to large strains by inverse modelling based on in-plane displacement fields. International Journal of Solids and Structures 2004;41(13):3439 -59. doi:http://dx.doi.org/10.1016/j.ijsolstr.2004.02.021.

[45] Eman J. Study and characterization of localization and failure behaviour of ultra high strength steel. Licenciate thesis; 2007. LuleåUniversity of Technology.

[46] Östlund R, Oldenburg M, Häggblad HÅ, Berglund D. Evaluation of localization and failure of boron alloyed steels with different microstructure compositions. Journal of Materials Processing Technology 2014;214(3):592 -8. doi:http://dx.doi.org/10.1016/j.jmatprotec.2013.09.022.

[47] Khan AS, Liu H. A new approach for ductile fracture prediction on al 2024-t351 alloy. International Journal of Plasticity 2012;35(0):1 - 12. doi:http://dx.doi.org/10.1016/j.ijplas.2012.01.003.

[48] Östlund R, Oldenburg M, Häggblad HÅ, Berglund D. Numerical failure analysis of steel sheets using a localization enhanced element and a stress based fracture criterion. International Journal of Solids and Structures 2015;56-57(0):1 - 10. doi:http://dx.doi.org/10.1016/j.ijsolstr.2014.12.010.

[49] Mura T. Micromechanics of defects in solids. 2. rev. ed.; Dordrecht: Nijhoff; 1987. ISBN 90-247-3343-X. 